\title{
Análisis proximal de granos de arroz, frijol, maíz y café comercializados en el mercado Roberto Huembes de Managua.
}

\author{
Samantha Miranda Calero \\ Laboratorio de Biotecnología. Universidad Nacional Autónoma de Nicaragua, Managua, \\ samcxrc@@hotmail.com \\ Jorge Esquivel Quezada \\ Laboratorio de Biotecnología. Universidad Nacional Autónoma de Nicaragua, Managua, \\ Juan Ruíz Urbina \\ Laboratorio de Biotecnología. Universidad Nacional Autónoma de Nicaragua, Managua, \\ Ena Rivers Carcache \\ Laboratorio de Biotecnología. Universidad Nacional Autónoma de Nicaragua, Managua
}

Fecha de recibido: 6 de abril de 2015

\section{RESUMEN}

Se realizó el análisis proximal de los granos básicos: arroz, frijol, maíz, así como del producto primario: café, comercializados en el mercado Roberto Huembes de Managua durante época de verano, a fin de obtener información sobre su composición nutricional. Las pruebas realizadas fueron: porcentaje de humedad, cenizas, proteínas y grasas. Los resultados mostraron diferencias entre los valores obtenidos y los valores de referencias a nivel de Centro América. El frijol distribuido presenta un alto contenido de proteínas $(23.87 \%)$, al igual que el maíz $(8.80 \%)$ y el café $(14.55 \%)$, sin embargo el porcentaje de grasa es variante para cada grano aunque en el maíz y el café los valores son inferiores a las referencias internacionales $(6.58 \%$ y $10.03 \%$, respectivamente). En el caso particular del arroz se determinó que la variedad estudiada presenta una composición inferior a los parámetros establecidos.

\section{Palabras claves}

Proximal, arroz, frijol, maíz, café
Fecha de aprobado: 12 de septiembre de 2015

\section{SUMMARY}

The proximate analysis of basic grains was made in rice, beans, corn, as well in a primary product like coffee. All the grains was marketed at Roberto Huembes market in Managua during summer time. The purpose of the investigation is obtain information on their nutritional composition. The tests performed were: percentage of moisture, ash, protein and fat. The results showed differences between the values obtained and the reference values at the level of Central America. The distributed bean has a high protein content $(23.87 \%)$, like corn $(8.80 \%)$ and coffee $(14.55 \%)$, while the percentage of fat is variant for every grain corn and although the coffee values are lower than international reference prices $(6.58 \%$ and $10.03 \%$, respectively). In the particular case of the studied variety of rice, it was determined that had a lower composition of the target parameters.

Keywords

Proximate, rice, bean, corn, coffee 


\section{INTRODUCCIÓN}

En Nicaragua, cultivo del frijol, arroz, maíz y café son fundamentales tanto por su importancia en la generación de trabajos, fomento del sector agrícola y, por ser uno de los principales pilares de la economía nacional, así como también por su participación en la alimentación diaria de la población. En general la dieta nacional está basada en cereales y, leguminosas. En esta combinación son fundamentales el maíz, el arroz y los frijoles como fuente de calorías y proteínas respectivamente. La dieta con base en frijol es común, combinada con arroz, maíz blanco y sorgo en dependencia de la zona agroclimática (MAGFOR, 2009).

De igual manera, el café representa un rubro de gran importancia para el país ya que además de formar parte de los 5 productos primarios que generan el 50\% de las exportaciones del país, producir el 20\% del PIB y proveer alrededor del $43 \%$ del empleo total, presenta un alto consumo por la población nicaragüense (MAGFOR, 2009).

Debido a la gran dependencia a todos estos granos, se hace imperativa la realización de análisis de su composición para determinar su aporte nutricional y para formular combinaciones nutritivas complementarias exitosas, información que actualmente no está disponible. El análisis de la composición proximal incluye parámetros como contenido de proteínas y de grasas cuya finalidad es meramente nutricional, y también incluye análisis de humedad y cenizas que definen tanto la identidad del alimento como su capacidad conservación (Organización de las Naciones Unidas para la Alimentación y la Agricultura (FAO, 1993)

Cabe mencionar que la composición química de los granos es afectada por múltiples factores, entre ellos plagas, condiciones edafoclimáticas, variedades, entre otros, por tanto la caracterización de los granos disponibles juega un rol importante para la seguridad alimentaria y nutricional como para el desarrollo de la agroindustria nacional. El objetivo de este estudio fue determinar la composición proximal de los granos comercializados en uno de los mercados de mayor afluencia de Managua.

\section{MATERIALES Y MÉTODOS}

Las muestras de granos de arroz, frijol, maíz y café fueron recolectadas en época de verano en comercios disponibles del mercado Roberto Huembes de Managua. Los granos se encontraban sanos libres de plagas y enfermedades. Las muestras se tomaron de forma aleatoria y correspondió 
a tres lotes de 5 libras cada uno, que conformó una muestra total de 15 libras y fueron colectadas en bolsas de polietileno debidamente identificadas. Los granos fueron procesaos en el Laboratorio de Biotecnología de la Universidad Nacional Autónoma de Nicaragua, Managua (UNAN-Managua).

\section{Preparación de las muestras}

Las muestras recolectadas fueron secadas al horno a $60^{\circ} \mathrm{C}$ durante 6 horas y posteriormente se obtuvo la harina de cada grano mediante su trituración en molino y maceración hasta alcanzar un tamaño de poro adecuado (tamiz $\mathrm{N}^{\circ} 30$ ). En el caso del maíz, su pericarpio fue removido antes de su preparación. Las harinas fueron almacenadas en refrigeración para evitar su degradación.

\section{Determinación de la composición proximal}

Todas las pruebas fueron realizados por triplicado, se incluyó un blanco y en base a los métodos oficiales de análisis de la Asociación Oficial de Químicos Analistas (AOAC; por sus siglas en inglés). La determinación de humedad se desarrolló en un horno de convección de aire en base a la AOAC 925.10, utilizando una temperatura de $130^{\circ} \mathrm{C}$ para llevar a peso constante las muestras cuyos tamaños fueron de $5 \mathrm{~g}$ para el arroz, frijol y café, y $8 \mathrm{~g}$ para el maíz.

El análisis de cenizas se realizó en una mufla según la AOAC 923.03 con temperaturas de $550^{\circ} \mathrm{C}$ para el arroz, frijol, café y $600^{\circ} \mathrm{C}$ para el maíz. La determinación del contenido de grasas se fundamentó en la AOAC 920.39 haciendo uso del equipo Soxhlet y éter de petróleo como solvente. El tamaño de la muestra fue homogenizada a 10g, sin embargo debido a que los tiempos de extracción varían, siendo el más prolongado la extracción del café (16 horas) se utilizó mayor volumen de solvente $(150 \mathrm{ml})$.

Finalmente el análisis del contenido de proteínas se realizó en base del método AOAC 2001.11 donde se realizó una modificación debido a los equipos disponibles (bloque digestor Labconco Rapid Digestor-4 y el micro-destilador Labconco RapidStill I). El tamaño de la muestra fue diferente para cada matriz sin embargo el tiempo de digestión fue el mismo (60 minutos).

El control de calidad de las muestras incluyó el análisis de muestras enriquecidas y blancos enriquecidos para verificar los porcentajes de recobro de cada uno de los análisis, esto fue contrastado con valores estándar y el blanco de cada prueba. El análisis estadístico de los datos se 
realizó en base al promedio de las lecturas por tanto se incluyó la determinación de la media y la desviación estándar de los resultados obtenidos así como de los límites permisibles con un límite de confianza del $95 \%$.

\section{RESULTADOS}

Los resultados del análisis proximal de las harinas de los granos estudiados demuestran la alta divergencia entre sus composiciones básicas (tabla $\mathrm{N}^{\circ} 1$ ). Los datos mostrados se obtuvieron como resultado de pruebas realizadas por triplicado, reportándose únicamente los valores promedio corregidos con el blanco de laboratorio para cada análisis.

Tabla $N^{\circ}$ 1: Composición proximal de las harinas de los granos colectados en el mercado Roberto Huembes.

\begin{tabular}{|c|c|c|c|c|}
\hline Matriz & Humedad (\%) & Cenizas (\%) & Grasas (\%) & Proteínas (\%) \\
\hline Arroz & 12.27 & 0.27 & 0.42 & 6.29 \\
\hline Frijol & 12.32 & 3.41 & 1.62 & 23.87 \\
\hline Maíz & 10.07 & 1.94 & 6.58 & 8.80 \\
\hline Café & 6.06 & 4.34 & 10.03 & 14.55 \\
\hline
\end{tabular}

\section{DISCUSIÓN DE RESULTADOS}

La determinación de la composición química proximal de los granos recolectados nos proporciona la información nutricional base para la elaboración de guías nutricionales efectivas para utilizarse en la dieta básica. Así mismo el contenido de humedad de las matrices influye directamente en el mantenimiento del mismo y sobre los métodos de conservación a utilizar.

\section{Frijol}

El porcentaje de humedad determinado es superior al reportado por Henríquez (2014) en su estudio de variedades Chaparrastique y China de El Salvador. De igual manera supera los valores establecido por el Departamento de Agricultura de Estados Unidos (USDA, por sus siglas en inglés) y por el Instituto de Nutrición de Centro América y Panamá (INCAP) (2012).

Por otro lado, el porcentaje de cenizas obtenido fue ligeramente superior al definido por el INCAP (2012) y similar al obtenido para las variedades salvadoreñas establecidas por Henríquez (2014). 
El porcentaje de grasas identificado es inferior al reportado para las variedades salvadoreñas, pero similar al rango establecido por el INCAP para variedades de Centro América de frijol rojo (1.06\%). En relación al porcentaje de proteína, el valor obtenido es superior al definido por el INCAP (22.53\%) sin embargo es inferior en comparación con la variedad China estudiada en El Salvador (27.05\%).

\section{Arroz}

El porcentaje de humedad, porcentaje de grasa y porcentaje de proteínas determinados en el arroz, fueron ligeramente inferiores a las reportadas por la tabla de composición de los alimentos del INCAP (2012), las cuales fueron de $12.89 \%, 0.58 \%$ y $6.61 \%$, respectivamente.

Mientras, el resultado del \% de cenizas obtenido fue superior al indicado por la organización antes mencionada $(9 \mathrm{mg})$. Estos resultados nos indican que existen otras variedades con mayor contenido nutricional aunque mayor contenido de agua presente.

\section{Maíz}

Otro de los granos básicos de importancia y de mayor consumo nacional es el maíz. Dentro de los resultados obtenidos encontramos que en comparación con los valores establecidos por el INCAP (2012) de la siguiente manera: $12 \%$ de humedad, $8.4 \%$ de proteína, $1.2 \%$ de grasa y $0.60 \mathrm{mg}$ de cenizas, el maíz disponible en el mercado nacional presenta un menor contenido de humedad aunque mayor porcentaje de proteínas, cenizas y notablemente, de grasas.

Así mismo, en comparación con los valores registrados por Ramírez (2006) de la variedad amarilla mexicana: $8.91 \%$ de humedad, $1.46 \%$ de cenizas, $10.25 \%$ de proteínas y $6.04 \%$ de grasas, presenta menor contenido de agua, aunque mayor contenido de cenizas, proteínas y grasas.

\section{Café}

Como ya fue mencionado, el impacto de este cultivo primario a nivel nacional es muy alto y debido a su alto consumo, su caracterización es de alta prioridad. De esta forma, al comparar los resultados obtenidos con los determinados por el INCAP (2012) en su tabla de composición de alimentos, donde se establece: $5 \%$ de humedad, $12.6 \%$ de proteínas, $14.8 \%$ de grasas y $4.8 \%$ de cenizas; podemos definir que el porcentaje de humedad, proteínas y cenizas de la variedad comercializada es superior, sin embargo el porcentaje de grasas es inferior a lo registrado por la entidad Centroamericana. 


\section{CONCLUSIONES}

Se determinó la composición proximal de los granos básicos disponibles en el mercado Roberto Huembes, donde encontramos que el frijol comercializado posee un alto contenido de proteínas en comparación a otras variedades de Centro América.

Desde el punto de vista nutricional, el arroz estudiado presenta una composición inferior a otras variedades de América Central, sin embargo cumple con los rangos establecidos.

Por otro lado, la variedad nacional de maíz disponible en el mercado es una variedad rica en proteínas y grasas con un bajo porcentaje de humedad, representando un buen aporte a la dieta de la población.

En relación al rubro café, un producto primario de gran importancia, podemos concluir que la variedad comercializada presenta un alto porcentaje de proteínas y un bajo porcentaje de grasas en comparación con valores de referencia Centroamericanos.

\section{RECOMENDACIONES}

Debido a la importancia de la composición nutricional de los granos básicos y en general de los alimentos de uso común en la dieta diaria, se recomienda realizar análisis proximal de otras variedades disponibles o variedades certificadas por instituciones nacionales como el Instituto Nicaragüense de Tecnología Agropecuaria (INTA), definiendo las condiciones agroecológicas en las cuales fueron cultivados.

\section{AGRADECIMIENTO}

Esta investigación no sería posible sin el apoyo técnico-analítico de la Dra. Katia Montenegro y la Lic. Martha Jarquín Pasquier, por tanto agradecemos el tiempo y soporte brindado.

\section{REFERENCIAS}

Food and Agriculture Organization of the United Nations (FAO). Manual de Técnicas para Laboratorio de Nutrición de Peces y Crustáceos. 1993. México D.F. 
Henríquez Guardado, F. 2014. Comparación de la calidad culinaria y del análisis bromatológico proximal de la especie Phaseolus vulgaris L. (frijol común) variedad Chaparrastique y la importada de China. Tesis inédita de licenciatura. Universidad de El Salvador. San Salvador, El Salvador

Instituto de Nutrición de Centro América y Panamá (INCAP). Tabla de composición de alimentos de Centro América. 2012. Guatemala

Ministerio Agropecuario y Forestal (MAGFOR). Fortalecimiento al Sistema Nacional de Semilla: Evaluación Social de Territorios. 2009. Managua, Nicaragua

Ramírez Moreno, E. 2006. Determinación de la composición química proximal y fibra dietaria de 43 variedades criollas de maíz de 7 municipios del Sur-este del estado de Hidalgo. Tesis inédita de licenciatura. Universidad Autónoma del Estado de Hidalgo. Pachuca, Hidalgo. México 